\title{
Climate Change: Its Causes, Effects and Control
}

\author{
Samaila Kakaki \\ Department Of Biology, Kaduna State College Of Education \\ Gidan-Waya, Kafanchan-Nigeria
}

\section{Doi:10.5901/jesr.2013.v3n10p73}

\begin{abstract}
One of the most controversial issues about the environment today is the issue of climate change. This phenomenon has been observed over time, with changes in weather patterns and climatic factors like temperature, pressure, and humidity. The cause is either human induced through the burning of fossil fuels and release of chlorofluorocarbons; or naturally through volcanic eruptions and continental plate movements. The evidence of climate change has been obtained from changes in weather patterns, global warming, vegetation changes, precipitation and archeology. These changes have resulted in negative consequences for the environment like drought, flood and depletion of the ozone layer. It has also caused serious health problems leading to deaths of people, decreased food production from unsteady rainy seasons and loss of biodiversity. Measures that can be taken to control it include: use of renewable energy sources, afforestation and strict government policies on emissions of carbon dioxide.
\end{abstract}

Keywords: Climate change, environment, weather, greenhouse gases, global warming.

\section{Introduction}

Climate change is having an impact on our planet and its life. It is widely regarded as the most disturbing problem facing the environment worldwide. The problems caused by rising seas, growing deserts and more frequent droughts all look set to affect the developing world more than the developed countries now and in the future. This has become one of the world's most controversial and hotly debated topics, with accusations and counter-accusations flying forth on who is responsible for it, which have done little to stem the ever-increasing tide of environmental problems. But, in the first instance, what, exactly, is climate change?

\section{Climate change}

This is a significant and lasting change in the statistical distribution of weather patterns over periods ranging from decades to millions of years. It may be a change in average weather conditions, or in the distribution of weather around the average conditions (National Aeronautics Space Agency, NASA, 2011). Solomon, Plattner, Knuti and Friedlingstein (2009) say it is the irreversible change in the climate due to carbon emissions.

\section{Evidence of climate change}

1. Global warming: This is the gradual increase of tropospheric temperature due to excessive emission and concentration of greenhouse gases leading to climate change and rising sea levels (NASA, 2011). The Intergovernmental Panel on Climate Change (IPCC, 2003), defined global warming as an increase in the earth's temperature that is caused by human activities such as bush burning and burning of coal, oil and natural gases like methane. 
2. Changes in weather patterns: Climate change has led to widespread changes or shifts in weather patterns worldwide. IPCC (2003) has noted that the times of the year in which seasons occur have changed. Rainfall comes later in the year and lasts into much later months than was usual. This has resulted in rain falling in months which are usually dry. An example is the heavy rains experienced in Gidan-waya, Kaduna State in December and January from 2009 to 2013. Curiously, this happened in months which are the height of the dry, cold and dusty harmattan period. The rainy season here has also come in full from February/March as against the usual May/June within the same period (2009 2013). Winter temperatures in very cold countries have become warmer. The CNN reported in May, 2001 that snow was seen melting in Sibeira, Russia in the middle of winter for the fist time in recorded history.

3. Ice core: Evidence of changes in the thickness of the ice sheets of Alaska covering millennia were obtained by boring holes into the ice. This showed an average increase of 0.5 degrees Celsius for every 100 years for the past 10,000 years. Changes in carbon dioxide levels trapped in the ice also show evidence of changes in climate (Christner, Morris, Foieman, Cai \& Sands, 2008).

4. Melting polar ice packs/glaciers and rising sea levels: According to Christner et al (2008), this is one of the most well known evidence of climate change. Polar ice caps have been melting and some estimates put the reduction by as much as 30\% over the past 20 years. The melting of the polar ice caps has resulted in rising sea levels with floods resulting in many places. The melting ice packs are being lost at an average of $11.5 \%$ per decade from 1970 to the present. A compilation of 100,000 glaciers from 1970 to 2013 show a decline in glacier cover. The World Glacier Monitoring Service, which collects data on glaciers annually, found that glaciers reduced significantly in the 1940s, were stable or growing in the 1920s and 1970s, and are retreating again from the mid-1980s to the present (Siez and Foppa, 2007).

5. Vegetation: Changes in type and distribution of vegetation are sure indicators of climate change. Some changes in climate result in increased precipitation and warmth, leading to increased vegetation growth, earlier flowering and fruiting, and subsequent sequestration of air-borne carbon dioxide. Some changes in climate will result in the reverse. Tracking of the world's vegetation with satellites have shown such variations.

6. Precipitation: Kasting and Seifert (2002) stated that past precipitation can be estimated in the modern era with the global network of precipitation gauges interpolated with satellite data which has been available since the 1970s. These show the earth to have been wetter during the Atlantic period (about 8000 years ago) with a progressive reduction in precipitation and a gradual drying up coming to the present day.

7. Archaeological/historical/oral evidence: These offer insight into climate changes in the past; how changes in climate have been linked with the rise and fall of some great civilizations.

\section{Causes of climate change}

According to Speelman (2009), climate change may either be human-induced, or a natural process that takes place without man's intervention. But the scientific consensus on climate change is that it is caused by man and the effects are largely irreversible (United States Research Council, 2007).

i. Human/anthropogenic causes: These include emissions of carbon dioxide from the combustion of fossil fuels which deplete the ozone layer, leading to global warming. Manmade factors also include bush burning, smoke emissions from industrial plants, methane gas from waste (refuse), chemical processes, nuclear fusion and fission, quarrying and mining. The human causes of climate change also include the following:

a. Deforestation: This is the destruction of the vegetation as a result of the activities of 
man and his domestic animals, or in search of economic benefits. It is a well known fact that vegetation is important in reducing carbon dioxide by absorbing it to perform photosynthesis and releasing oxygen, which in turn reduces the heating effect of the earth's atmosphere (IPPC, 2003). As such, the cutting down of trees results in a situation whereby the amount of carbon dioxide released to be used up by vegetation is much higher than the vegetation now present can absorb.

b. Greenhouse gases: Named after the greenhouse effect, the gases released from industries, vehicles and bush burning form an invisible particle/gas layer in the upper atmosphere. This reflects back solar radiation reflection back off the earth's surface. This increases the temperature on the earth's surface (Mader, 2010).

c. Ozone layer depletion: Ozone is an unstable triatomic $\left(\mathrm{O}_{3}\right)$ molecule of oxygen it occurs at about 20 kilometers above the earth's surface. It protects the earth by deflecting back much of the ultraviolet rays of the sun. It is very unstable and one of its molecules is easily displaced to reduce it to a diatomic molecule $\left(\mathrm{O}_{2}\right)$. Gases like carbon dioxide and chlorofluorocarbons (CFCSs) do this easily. When the ozone is depleted, a "hole" is formed through which ultraviolet rays pass and increase the surface temperature. This is very noticeable in heavily industrialized cities like Tokyo, Manchester and Detroit (Mader, 2010).

ii. Climate forcing/natural mechanisms: These include variations in solar radiation, variations in the earth's orbit, mountain building, continental drift and changes in naturally emitted greenhouse gas concentrations. A hypothesis among a consensus of scientists believes that climate change is a natural variability. Other natural factors include volcanic eruptions like those of Mounts Tambora in 1815, Krakatoa in 1883, Novarupta in 1912 and Pinatubo in 1991 which threw up large quantities of ash which blocked off the sun's rays from reaching the earth's surface for a few years, lowering the earth's surface temperature by 0.5 degrees Celsius (Oppenheimer, 2003). It is curious to note that published studies show that annual volcanic emissions of carbon dioxide including from mid-volcanic ridges, volcanic arcs and hot-spot volcanoes are only equivalent to human caused output (Diggles, 2005 and Adams, Hughton, Fagents \& Hildereth, 2006).

\section{Effects of climate change on humans and the environment}

1. Increased average annual temperatures: Studies have shown that the earth's average annual temperature has increased by 5 degrees Celsius. This has resulted in hot dry regions becoming hotter and drier, and cold regions becoming warmer. High temperatures increase the number of people who die in a given day. The Kyoto Protocol (2001) states that the earth's temperature is being increased due to emissions of greenhouse gases and associated human activities such as burning of fossil fuels, biomass burning, cow and sheep rearing, and other land use changes. That climate change is characterized by global warming leading to large scale irreversible effects at the continental and global scales. The likelihood and magnitude of the effects are observed and predicted to be increasing and accelerating.

2. Natural disasters: The change in weather patterns have come with devastating impact on nature with increased flooding, drought and unpredictable weather. A harrowing example is what happened in Mozambique in 2003, when unusually high rainfall levels resulted in a 300 - meter wide river swelling to a 16-kilometer-wide torrent of death.

3. Unsteady food production: Man's basic needs are food, shelter and clothing (in that order), so if a country cannot feed itself because of weather changes, the consequences can only be imagined. Climate change, with increasingly erratic weather patterns, has impacted negatively on food production with farmers sometimes planting corps out of season. The attendant negative economic and social consequences are of great concern. 
By December 2007, 37 countries faced food crises which have shown no sign of abating six years on. On April 29, 2008, UNICEF United Kingdom found that climate change is already reducing the quality of the world's most vulnerable children's lives and also access to clean water and food supplies particularly in Africa and Asia. Masoheng and Running (2010) said the increase in average global temperature is a major environmental hazard leading to possible weather changes affecting agriculture output.

4. Extreme weather variations: Apart from the aforementioned changes in weather patterns, climate change also causes extreme weather variations like the heat wave which cut a swath through mid-Western USA in April and May 2012. This sort of extreme weather change was exemplified by a CNN report in 2001 showing ice melting during winter in Siberia, Russia, for the first time in recorded history. Anticipated direct consequences of climate change include injury and death from extreme weather changes and natural disasters.

5. Drought: Rainfall has decreased in many places resulting in failed crops. This has caused starvation and death in many places, especially in the Northern part of Nigeria. People and livestock have to move further distances to obtain drinking water. This has caused serious conflicts between communities, especially between nomadic cattle rearers and farmers.

6. Desertification: Associated with prolonged drought, deserts are encroaching into Nigeria rapidly. This spells doom for the future.

7. Health crises: During a twenty-year period 1979 - 1999, a total of 3,829 deaths in the United States were associated with excessive heat due to extreme weather conditions. In the same period, a total of 13,970 deaths were attributed to hypothermia, a condition caused by extremely low temperatures (IPCC, 2003). The aforementioned heat wave in mid-Western USA in April and May 2012 resulted in several deaths of the elderly and infirm in the city of California.

8. Loss of biodiversity: Changing weather patterns disrupt the lifestyle of organisms. The slightest change in environmental factors like temperature, pressure, light intensity, wind speed and humidity affect the life patterns of animals and adaptations of plants, thereby endangering their very existence. Those which cannot adapt will die out (Mader, 2010). The losses of polar ice caps and glaciers have impacted negatively on animals like polar bears, seals and walruses which depend on them for their survival.

\section{Control of climate change}

Most activities that lead to climate change are as a result of human activities. The IPCC (2003) emphasized on the need for strict penalties and stiff measures against those involved in activities causing climate change. It also advocated for strong environmental laws to be made against the habit of burning of bushes, deforestation and desertification to control the effects of climate change. It also stated that if the countries are mapped, it would be used to check the effect of global warming in the country and necessary measurers can be taken to control it. It also suggested that the use of renewable energy sources like wind power are means of reducing carbon dioxide emissions.

The IPCC (2003) gives the following ways to control climate change.

i. Renewable energy sources: Using energy more efficiently with renewable energy (wind, solar, geothermal and bioenergy) would significantly reduce our emission of heat-trapping gases.

ii. Afforestation: Planting of trees is an efficient remedy for global warming. Varieties of tree species that consume high amounts of carbon dioxide during photosynthesis should be planted.

iii. Reduced refuse cycle: Reducing the use of disposables and buying products with minimal packaging would help to reduce waste recycling (papers, plastics, newspapers). 
iv. Policies: Policies should be made which would regulate, or stop completely, activities which could contribute to climate change. Governments can involve business leaders because of their influence and also solicit for the support of concerned citizens.

\section{References}

Adams N.K.; Houghton, B.F.; Fragent S.A; \& Hilderth W., (2006). The transaction from explosive to effusive eruptive regime: The example of the 1912 Novarupta eruption, Alaska. Geological Society of America Bulletin. 118 (5 - 6): 620.

Christner B.C; Morris C.E.; Foreman C.M; Cai R.; \& Sands T.C, (2008). Ubiquity of biological ice nucleators in snowfall. Science 319 (5867). 1214.

Diggles M., (2005). The cataclysmic 1991eruption of Mount Pinatubo. Philippines. U.S. Geological Survey Fact Sheet. 113 - 97.

Intergovernmental Panel on Climate Change (2003). An Article on Global Warming in Africa.

Kasting J.F; AND Seifert J.L., (2002). Life and evolution of the earth's atmosphere. Science 296: 1066 1068.

Mader, S.S. (20100. Biology: inquiry into life. McGraw-Hill Companies, Mexico City.

Maosheng Z. and Running S.W (2010). Drought-induced reduction in global terrestrial net primary production from 2000 through 2009. science 329 (5994) 940 - 3.

National Aeronautic Space Agency (NASA, 2011). What's in a name? global warming vs climate change.

Oppenheimer C., (2003). Climatic, environmental and human consequences of the largest known historic eruption: Tambora volcano (Indonesia) 1815. Progress in Physical Geography. 27 (2): 230. 43

Siez G., and Foppa M., (2007). The activities of the world glacier monitoring service (WGMS). http://www.meteoswiss.admin.ch. web/en/climate/cimate internatinal/gas/inventory/wgms.

Solomon S.; Plattner G.; Knuti r., and Friedlingstein P., (2009). Irreversible Climate Change due to carbon dioxide emissions. Proceedings of the National Academy of Sciences of the United States of America. 106 (6): 1704 - 9.

Speelman, E.N. (2009). The eocenicrctic arctic azolla bloom: environmental conditions, productivity, and carbon drawn down. Geobiology, 7, 155 - 170. 
